\title{
It doesn't hurt to ask: Question-asking increases liking.
}

\section{Citation}

Huang, Karen, Michael Yeomans, Alison Wood Brooks, Julia Minson, and Francesca Gino. "It Doesn't Hurt to Ask: Question-Asking Increases Liking." Journal of Personality and Social Psychology 113, no. 3 (September 2017): 430-452.

\section{Published Version}

doi:10.1037/pspi0000097

\section{Permanent link}

http://nrs.harvard.edu/urn-3:HUL.InstRepos:35647952

\section{Terms of Use}

This article was downloaded from Harvard University's DASH repository, and is made available under the terms and conditions applicable to Open Access Policy Articles, as set forth at http:// nrs.harvard.edu/urn-3:HUL.InstRepos:dash.current.terms-of-use\#OAP

\section{Share Your Story}

The Harvard community has made this article openly available.

Please share how this access benefits you. Submit a story.

Accessibility 
RUNNING HEAD: Question-asking

\title{
It Doesn't Hurt to Ask:
}

\section{Question-Asking Encourages Self-Disclosure and Increases Liking}

\author{
Karen Huang, Mike Yeomans, Alison Wood Brooks, Julia Minson, Francesca Gino \\ Harvard University
}

\begin{abstract}
Acknowledgements
We are grateful for insightful feedback from the Harvard Business School's GiNorton Lab members, the University of Chicago's Behavioral Science seminar participants, the Wharton School's OID seminar participants, and research assistance from Ethan Ludwin-Peery, Ashley Kirsner, Jean Sohn, Elise Lee, and Isabelle Moore. All errors in the manuscript are our own. Data are available from the corresponding author, Karen Huang (khuang@hbs.edu).
\end{abstract}




\begin{abstract}
Conversation is a pervasive human experience, one that is necessary to pursue intrapersonal and interpersonal goals across myriad contexts, relationships, and modes of communication (e.g., written, spoken). In the current research, we isolate the role of an understudied conversational behavior: question-asking. Across four studies, we identify a robust and consistent relationship between question-asking and liking: people who ask more questions are better liked, and speed daters who ask more questions get more second dates. The effect of question-asking on liking is causal and holds even when people are instructed to ask a high number of questions. We find that question-asking only influences individuals engaged in the conversation; third-party observers do not show the same increased liking of the question-asker. Our results suggest that question-asking affects liking in dyads because it solicits self-disclosure from the question answerer. Self-disclosure is enjoyable, and question answerers attribute this enjoyment to the question asker. Despite these persistent effects, people do not expect the amount of questions they ask to influence others' perceptions.
\end{abstract}

Keywords: Question-asking; Self-disclosure; Liking; Impression management; Conversation

Disclosure: For each study, we report how we determined our sample size, all data exclusions, all manipulations, and all measures. The exact data from each study are available as Online Supplementary Materials at https://osf.io/8k7rf/ 


\section{It Doesn't Hurt to Ask: \\ Question-Asking Encourages Self-Disclosure and Increases Liking}

Imagine this scenario: you meet a new colleague for the first time at a company party. You strike up a conversation, and the colleague tells you a funny story. You are interested and engaged, and you ask several questions during the story. After the story is over, you exchange pleasantries and part ways. Later you realize that your colleague didn't ask any questions about you, and you didn't reveal much information about yourself. You wonder who made a better impression.

Conversation is a pervasive human experience, one that is necessary to pursue intrapersonal and interpersonal goals across myriad contexts, relationships, and modes of communication (e.g., written, spoken). We converse with others to learn what they know-their knowledge, stories, preferences, ideas, thoughts, and feelings—and to share what we know while managing others' perceptions of us. That is, two central conversational goals are 1) information exchange and 2) impression management. In this paper, we examine a conversational tool that likely influences both of these goals: question-asking.

Although question-asking is ubiquitous, we know very little about the antecedents and consequences of asking questions during interpersonal interaction. In the current research, we investigate the psychology of question-asking as a social phenomenon. We measure people's natural rates of question-asking and explore how the propensity to ask questions influences interpersonal liking in both laboratory and field settings. Compared to people who ask few questions, we expect that high question askers are better liked because their questions invite selfdisclosure from their conversation partners. 


\section{Question-Asking in Conversation}

Prior research describes a conversation as a cooperative interaction between people. Each conversationalist acts in coordination to contribute to a successful experience of shared understanding (Clark \& Schaefer, 1989). Though not all, most conversations are characterized by the transfer of information about beliefs, thoughts, or emotions from one person to another (Epley \& Waytz, 2010).

There are many ways people can express themselves during a conversation, such as making a factual statement, making a quip or joke, or giving a compliment. In the current work, we explore a ubiquitous but understudied conversational tactic: question-asking. Question-asking directs conversations by encouraging the other person to actively share information (Dillon, 1982, 1988), and most questions function to solicit information from the other person (Chafe, 1970; Dillon, 1982; Kearsley, 1976). If one person asks a question, the other person should follow with a response that abides by basic conversational maxims (Graesser, 1985; Grice, 1975), such as responding at an appropriate length, and responding to the question at hand (Hilton, 1990), though recent work suggests that people sometimes violate these norms by dodging questions and paltering (Rogers \& Norton, 2011; Rogers \& Norton, 2016).

In our research, we focus on information-seeking questions (e.g., Miles, 2013; Van der Meij, 1987), in which the question-asker is missing a piece of information and, by asking a question, seeks the answer from another person. People often ask information-seeking questions when meeting for the first time (Berger \& Calbrese, 1975). People are also more likely to seek information from another person when they consider the information to have high utility (Swann, Stephenson, \& Pittman, 1981). Because people often know very little about each other upon first meeting, individuals stand to learn a large amount about their conversation partners and to 
benefit from the unique, novel information their conversation partners may have to share during first encounters. Importantly, though, information exchange is not the only goal of conversation. Asking questions may serve and influence other motivations like impression management.

\section{Question-Asking and Liking}

Most people have an intrinsic desire to be liked by others (Baumeister, 1982; Jones \& Pittman, 1982; Leary \& Kowalski, 1990). A large body of prior research suggests that the content of a conversation can significantly influence the extent to which the conversationalists like each other when the conversation is over. The effect of conversational content on interpersonal liking has been demonstrated across a wide array of conversational strategies, ranging from other-focused behaviors, such as giving a compliment or acknowledging another person's ideas, to self-focused behaviors, such as talking about oneself (Godfrey, Jones, \& Lord, 1986; Laurenceau, Barrett, \& Pietromonaco, 1998; Rosenfeld, 1966; Sprecher, Treger, Wondra, Hilaire, \& Wallpe, 2013). But, to our best understanding, no prior work has investigated the effect of asking questions on interpersonal liking.

Though asking questions invites information exchange, there are many reasons why people do not ask questions. For example, people may forgo asking questions because they are unsure about what to ask or worry about asking a question that is perceived as rude or inappropriate. Still others may forego asking questions in dyadic conversation because they are egocentric, focusing on and expressing their own thoughts, feelings, and beliefs (e.g., Gilovich, Medvec, \& Savitsky, 2000) with little to no interest in learning what their conversation partner has to contribute. Indeed, in most conversations, people predominantly share information about themselves rather than discussing other possible topics (Landis \& Burtt, 1924). A study of conversations in public settings like bars and trains suggests that people spend two-thirds of 
conversation time talking about their personal experiences (Dunbar, Marriott, \& Duncan, 1997). Especially when meeting someone new, people tend to use self-focused presentation strategies like self-promotion (Godfrey et al., 1986). For example, extant work by Marr and Cable (2014) suggests that job candidates excessively attempt to "sell" themselves to make a favorable impression in job interviews.

The tendency to focus on the self when trying to impress others is misguided, as verbal behaviors that focus on the self, such as redirecting the topic of conversation to oneself, bragging, boasting, or dominating the conversation, tend to decrease liking (Berman, Levine, Barasch, \& Small, 2015; Godfrey et al., 1986; Sezer, Gino, \& Norton, 2015; Vangelisti, Knapp, \& Daly, 1990). In contrast, verbal behaviors that focus on the other person, such as mirroring the other person's mannerisms (Ireland \& Pennebaker, 2010), affirming the other's statements, or coaxing information from the other person, have been shown to increase liking (Godfrey et al., 1986; Rosenfeld, 1966). We hypothesize that question-asking is an other-focused conversational strategy that is likely to increase liking for the question asker. Because people mostly talk about themselves rather than asking questions, we hypothesize that people do not anticipate the interpersonal benefits of asking questions.

Hypothesis 1: Being asked questions increases liking toward the question asker.

Hypothesis 2: People do not anticipate the effect of question-asking on liking.

\section{Question-Asking Invites Self-Disclosure}

The link between self-disclosure and liking has long been a topic of interest to psychologists (for review, see Collins \& Miller, 1994; Cozby, 1973). Self-disclosure is defined broadly as the act of communicating personal information to another person (Collins \& Miller, 
1994; Cozby,1973; Omarzu, 2000), typically within the context of a dyadic interaction (Altman \& Taylor, 1973; Archer, 1979; Chaikin \& Derlega, 1974).

Prior research suggests that self-disclosure is intrinsically enjoyable (Cozby, 1973; Jourard \& Landsman, 1960; Jourard \& Lasakow, 1958; Omarzu, 2000). Indeed, disclosing personal narratives has been shown to increase positive affect and enhance psychological wellbeing (Pennebaker, 1985, 1989, 1997). Furthermore, disclosing information about the self is positively associated with neural regions of reward in the brain (Tamir \& Mitchell, 2012).

Disclosing may be especially enjoyable when it is invited with a question. In fact, people prefer to disclose to another person, even to an experimenter, rather than privately (Frattaroli, 2006; Lyubomirsky, Sousa, \& Dickerhoof, 2006). To assess the subjective value of disclosing information about the self, Tamir and Mitchell (2012) enabled participants to answer questions about the self or about another person, and their answers either remained private or were disclosed to another person. Participants were willing to forgo money to answer questions about the self (rather than questions about someone else), and they were willing to sacrifice even more money when those answers were disclosed to another person. Disclosing to another person could be particularly meaningful if the other person signals interest and positive approval (Chen, Minson \& Tormala, 2010; Cozby, 1973), implying that someone else is listening, understanding, or validating the disclosure (Davis \& Perkowitz, 1979; Laurenceau et al.,1998; Reis \& Patrick, 1996; Reis \& Shaver, 1988).

What induces self-disclosure? Early research on self-disclosure assumed that people voluntarily talk about themselves (Jourard, 1958), while more-recent work has examined selfdisclosure in response to experimenter-generated questions (A. Aron, Melinat, E. Aron, Vallone, \& Bator, 1997; Sprecher et al., 2013). Relatedly, Miller, Berg and Archer (1983) investigated 
individual differences in the extent to which people elicit self-disclosure from their conversation partners. They find that people who elicit a high amount of disclosure (termed "openers") are better-liked by their partners. To our knowledge, no prior work has considered how simply asking more questions might induce self-disclosure.

Attribution theory suggests that question-asking may boost liking precisely because it is enjoyable for the discloser. People tend to attribute events to the most salient possible cause (Pryor \& Kriss, 1977; Smith \& Miller, 1979; White, Fishbein \& Rutstein, 1981). In the context of a dyadic interaction, as the discloser experiences enjoyment from self-disclosing, he or she may infer liking for the question-asker as the most available explanation for that enjoyment. This prediction is consistent with Schacter and Singer's (1962) theory of emotion: when people experience arousal, they look for readily accessible explanations in the external environment. Furthermore, our prediction is consistent with previous findings that self-disclosers report liking for the recipient and high positive affect during the interaction (McAllister, 1980). Indeed, early work by Jourard (1959) suggests that positive feelings of self-disclosure become associated with the person who witnesses the disclosure.

Two previous lines of research suggest that this mechanism may be true. First, studies of doctor-patient communication show that when physicians ask more questions about the patient's experiences, patients talk longer about their psychosocial concerns and report higher satisfaction with the visit (Bertakis, Roter, \& Putnam, 1991). General-inquiry questions (e.g., "How are you feeling today?") allow patients to provide detailed information about their medical symptoms and affective experiences (Heritage \& Robinson, 2006; Roter \& Hall, 1987). This leads to significant increases in patients' positive evaluations of physicians' communicative behavior. These findings support the view that the intrinsic reward of self-disclosure, including the 
disclosure of medical information, becomes associated with the recipient of the disclosure (Robinson \& Heritage, 2006; Stiles, Putnam, Wolf, \& James, 1979).

Second, Brooks, Gino, and Schweitzer (2015) found that people enjoy being asked for advice and view people who seek their advice as more competent than those who do not seek their advice. This effect is egocentric: the boost in perceived competence holds only when the advisor is asked to rate the advice-seeker, and the effect disappears when a third-party observer rates the advice-seeker. The authors argue that this is because being asked for advice is flattering. It feels good to be asked, so the advisor views the advice seeker more favorably. This work suggests that, as in the case of advice, asking questions may only affect the liking of the question asker by the question answerer, and not by third-party observers.

Taken together, we predict that question-asking increases self-disclosure, which the question answerer enjoys. Question answerers, in turn, are likely to attribute the enjoyable experience of self-disclosure to the question asker and view him more favorably than a conversation partner who does not ask questions. Additionally, we predict that because egocentric self-disclosure is necessary for question-asking to increase liking, third-party observers will not show the same increase in liking for the question-asker.

Hypothesis 3: Question-asking increases self-disclosure, which explains the relationship between question-asking and liking.

Hypothesis 4: Question-asking does not increase liking of question askers by third-party observers (i.e., those who witness the conversation but do not answer the questions themselves).

\section{Overview of the Present Research}

In a series of four studies, we investigate the patterns and effects of question-asking in dyadic conversation. In a Pilot Study, we explore people's natural rates of question-asking. In 
Study 1, we instruct one conversation partner to ask a high or low number of questions and measure the other partner's liking of the question asker. In Study 2, we manipulate high or low question-asking for both conversation partners and investigate self-disclosure as a psychological mechanism. In Study 3, we ask third-party observers to watch a dyadic conversation and rate the conversation partners on a measure of liking. Finally, in Study 4, we investigate the effect of question-asking in a field context (speed-dating) with an objective behavioral measure of liking (being asked on a second date).

\section{Pilot Study}

We conducted a pilot study to observe the natural rate of question-asking during an interpersonal first meeting. The purpose of this study was to establish the average number of questions people ask in the paradigm we use in our main set of studies, and to establish high and low question-asking levels to use for our subsequent experimental manipulations.

\section{Participants}

We recruited 193 participants from a large university in the northeastern United States (all U.S. citizens) to participate in a behavioral laboratory study in exchange for $\$ 15$. We excluded 59 participants due to technical problems ${ }^{1}$ (exclusion criteria were decided a priori). The final sample for the Pilot included 134 participants (68 male, 66 female), or 67 dyads.

\section{Procedure}

We asked participants to sit in separate cubicles in our behavioral lab. All study materials were presented on separate computers, and participants did not interact face to face. Instead, participants interacted by sending each other instant messages using an interface called ChatPlat,

\footnotetext{
${ }^{1}$ Some participants accidently pressed the "backspace" or "next" button when they were typing, just as the chat was expiring, which redirected them to an error page. As a consequence, their chat partners were also redirected to an error page. These were technical problems due to the ChatPlat software that we could not control.
} 
an application that enables experimenters to pair people easily and allow them to chat with each other seamlessly within an online survey. ChatPlat has been used and validated in previous research (e.g., Brooks \& Schweitzer, 2011).

Based on their arrival time at the ChatPlat chat window (i.e., the first-arriving participant was matched with second arriver, and so on), participants were paired with another participant in the room. Before chatting, participants read these instructions: "You will be randomly paired with another participant to chat for fifteen minutes. During the conversation, your objective is to get to know each other." They chatted for 15 minutes, at which time the chat window closed and they could move on in the survey. Participants did not have a timer during the conversation but received a notification one minute before their chat was due to end. After each dyad finished their conversation, both participants completed several measures of interpersonal perception (see Appendix A for all measures collected). After the study was over, we asked a research assistant to code the conversation transcripts for the number of questions asked.

\section{Results}

Participants asked an average of 6.72 questions $(S D=4.16)$. We calculated the $25^{\text {th }}, 50^{\text {th }}$, and $75^{\text {th }}$ percentiles of the question-asking distribution to use as our experimental manipulation of low and high question-asking in our main set of studies. Rounded to the nearest whole number, these values were 4, 6, and 9 questions, respectively.

We also used these data to compare the accuracy of human-coded questions with a simple algorithm that counted sentences with question marks. The two methods were virtually identical (Cronbach's $\alpha=0.96$ ), and upon closer inspection of the discrepancies, neither method was reliably more accurate when they disagreed. Based on this result, we use the algorithmic question detector to count questions in all subsequent studies. 


\section{Study 1}

In Study 1, we test the effect of question-asking by randomly assigning one participant in a two-person conversation to ask either a high or a low number of questions. The other conversation partner did not know about the question-asking manipulation. After the conversation, both participants reported how they felt about the conversation and their partner. In addition to interpersonal perceptions, we also measured learning (i.e., information exchange).

\section{Method}

Participants. We recruited 430 participants (215 dyads) in an attempt to achieve a sample size that was double the sample size of the Pilot Study. We recruited participants to participate in a "Chat Study" in a behavioral lab. We applied several exclusion criteria that were determined a priori to ensure our analysis only considered dyads in which both participants completed the full survey. Accordingly, we excluded three dyads in which at least one partner did not finish the study, three dyads in which at least one partner indicated that he or she was not paired with another participant, and 10 dyads in which at least one partner reported that he or she was not able to complete a full conversation. These exclusions left a sample of 398 participants (194 male, 204 female), or 199 dyads, for our analyses.

We recruited participants in three different recruiting waves due to lab recruiting constraints. In one recruitment wave, participants completed only our study and were paid \$15. In two other recruiting waves, participants completed our study among a bundle of unrelated studies. In these latter cases, participants were paid \$20 and \$25 respectively. We found no differences in our results controlling for recruitment wave and report our results collapsed across all three waves. 
Design and procedure. We used the same procedure as in the Pilot Study with a few differences. First, at the beginning of the session, participants were told: "During the conversation, your objectives are for you and your partner to get to know each other and learn about each other's interests." Participants were paired based on their arrival time at the ChatPlat chat window. Conversation partners were anonymous, such that they did not know who their partner was in the room. Participants were told to pay attention during the chat because they would be asked to complete several questionnaires about their partner after they finished chatting. Participants then proceeded to chat for 15 minutes using the same instant messaging paradigm as in the Pilot Study.

In each dyad, one of the participants was randomly assigned to receive instructions about how many questions to ask; the other participant received no additional instructions. Those who received instructions were randomly assigned to one of two conditions: many-questions or fewquestions. In the many-questions condition, participants were told that they needed to ask "at least 9 questions." In the few-questions condition, participants were told that they needed to ask “at most 4 questions." These cut-offs were determined based on the 25 th and 75 th percentiles from the Pilot Study to ensure the number of questions would be noticeably different from an average conversation, but still natural. The participants who read these question-asking instructions were instructed to refrain from telling their partners they had been given additional instructions.

At the end of the chat, participants in all conditions reported their liking for their partner, and predicted their partner's liking of them (see Appendix B for the full list of measures). Participants' knowledge of their partner was measured using the Activity Preferences Questionnaire (APQ; Surra \& Longstreth, 1990; Swann \& Gill, 1997). We used the shortened 
APQ, a 9-item measure asking participants how much they like day-to-day activities (e.g. reading, cooking, exercising, etc.) on a 9-point scale, from dislike extremely to like extremely. Each participant completed a block where they gave their own answers to the APQ, and a block where they predicted how their partner would answer the APQ items, and the order of the two blocks was counterbalanced. Next, we included a manipulation check, asking participants if they were instructed to ask questions and, if so, how many questions.

\section{Results}

We compared all of the analyses below across recruitment wave and found no meaningful differences. We present our results collapsed across recruitment wave.

Question-asking. We analyzed question-asking using the algorithm's count of questions (number of questions asked) as well as questions as a proportion of all conversational turns (question rate). Consistent with our intended manipulation, participants who were instructed to ask many questions did in fact ask more questions $(M=10.23, S D=4.94)$ than participants who received no question-asking instructions $(M=7.03, S D=3.95$; two-sample t-test: $t(297)=6.06$, $p<.001$ ), who in turn asked more questions than those who were instructed to ask few questions $(M=4.34, S D=2.16$, two-sample t-test: $t(296)=6.31, p<.001)$. The same pattern held when questions were measured as a percentage of all conversational turns: those assigned to ask many questions had a higher question rate $(M=41.3 \%, S D=21.2 \%)$ than did the no-instruction participants $(M=29.3 \%, S D=15.8 \%$; two-sample t-test: $t(297)=5.52, p<.001)$, who had a higher question rate than those assigned to ask few questions $(M=23.6 \%, S D=17.3 \%$; twosample t-test: $t(296)=2.85, p<.001)$.

Liking. The primary dependent measure for this study was a block of four items about how much participants liked their partner after the conversation had ended (see Appendix B). 
These items were aggregated into a single standardized index of liking (Cronbach's $a=0.87$ ), and we depict the results by condition in Figure 1. Confirming our prediction, participants paired with high question-askers liked their partners more $(M=5.79, S D=1.21)$ than did participants paired with low question-askers $(M=5.31, S D=1.48$; two-sample t-test: $t(197)=2.47, p=$ 0.014; Cohen's $d=0.38$ ).

There was no difference in liking among the participants who received the questionasking instructions. Those who were instructed to ask many questions liked their partners just as much $(M=5.76, S D=0.94)$ as did participants who were instructed to ask few questions $(M=$ $5.67, S D=1.27$, two-sample t-test: $t(197)=0.51, p=.612)$.

Predicted liking. Predicted liking was reported on the same four items used to measure liking, but participants were asked to anticipate their partner's liking of them (Cronbach's $a=$ 0.85, see Appendix B). There were no differences between participants who were instructed to ask many questions $(M=5.27, S D=.93)$ or few questions $(M=5.19, S D=1.05)$, or who received no instructions for question-asking $(M=5.15, S D=1.14$, all $p s>0.5)$. Across all conditions, there was also no correlation between participants' predicted liking and their question-asking rate $(r=-0.013, t(396)=0.22, p=0.830)$. These results suggest that participants did not think that question-asking had an effect on liking.

Interpersonal Perception Accuracy. The eight APQ items were condensed into a single metric of interpersonal perception accuracy, based on previous research (Shrout \& Fleiss, 1978; Swann \& Gill, 1997). Comparing across groups, participants assigned to ask a lot of questions were slightly more accurate $(M=0.322, S D=0.313)$ than participants assigned to ask few questions $(M=0.270, S D=0.317$, two-sample t-test: $t(196)=1.16, p=0.246)$, and significantly more accurate than participants who received no question-asking instructions $(M=0.234, S D=$ 
0.306 , two-sample t-test: $t(295)=2.33, p=.021)$. Furthermore, within the group of participants who did not receive instructions, there was a significant correlation between their own questionasking rate and accuracy $(r=0.254, t(196)=3.68, p<.001)$.

\section{Discussion}

In this study, we tested the effect of asking many or few questions in a conversation. When one conversation partner was instructed to ask many (9) or few (4) questions, their conversation partners liked the high question-askers more than they liked the low questionaskers. The participants did not anticipate the effect of question-asking on liking. In addition to being better-liked, participants who were assigned to ask more questions also learned more about their partners. These results show clear benefits to asking questions for both the question asker and the question recipient.

\section{Study 2}

In Study 1, only one person received instructions about how many questions to ask. This approach allowed us to understand perceptions of high and low question askers without experimentally tainting the rater's perspective. However, it is unclear how conversations proceed when both people ask many questions, both people ask few questions, or one person asks many while the other asks few. In Study 2, we pursued these dynamics by randomly assigning all participants to either high or low question-asking conditions in a 2 (high v. low question asking) x 2 (high v. low question asking) design.

\section{Method}

Participants. Participants were recruited from Amazon's Mechanical Turk for a “Chat Study." We recruited a total of 446 participants to target a sample that was the same size as the 
sample size in Study 1. From that group, we applied the same a priori exclusion criteria as in Study 1 (because the sample was collected online, there were naturally more technical challenges that lead to exclusions). We excluded 15 dyads where at least one participant did not finish the study. We excluded 28 dyads that contained a duplicate IP address and three dyads that contained a duplicate MTurk ID. Finally, we excluded eight dyads where participants reported that they were not able to complete a full conversation. After exclusions, our final sample included 338 participants (177 male, 161 female), or 169 dyads, for our analyses.

Design and procedure. Before starting their conversation, all participants were given the same instructions as in Study 1 and told their objective was "to get to know each other." The text of the question-asking instructions was also the same (i.e. "ask [at most 4/at least 9] questions"). As in Study 1, we measured liking and predicted liking as our main dependent variables (see Appendix B for all measures collected.)

The most important difference from Study 1 is that both participants in each conversation were given question-asking instructions. Each participant was assigned randomly to ask either many or few questions, and they were assigned to their condition independently. This ensured that one-quarter of pairs were both assigned to ask many questions, one quarter of pairs were both assigned to ask few questions, and the remaining pairs included one partner assigned to ask many and one partner assigned to ask few.

\section{Results}

Manipulation check: Questions asked. Across all conditions, individual participants asked 5.98 questions $(S D=3.63)$, on average. Following the instructions, participants who were told to ask many questions did in fact ask more questions $(M=8.78, S D=3.15)$ than participants who were told to ask few questions $(M=3.52, S D=1.78$; two-sample t-test: $t(336)=19.14, p<$ 
.001 ; Cohen's $d=1.45)$. This difference also held when we computed question-asking as a fraction of total conversational turns: high-question participants had a higher question rate $(M=$ $49.6 \%, S D=22.8 \%)$ than did low-question participants $(M=24.6 \%, S D=18.3 \%$; two-sample ttest: $t(336)=11.15, p<.001$; Cohen's $d=1.04)$. There was no effect of the partner's condition on one's own question rate (all $p s>0.3$ ). This confirms that our manipulation had its intended effect on how participants conducted their conversations.

Liking. Participants reported their liking for their partner using the same four items as in Study 1 (see Appendix B). These items were aggregated into a single standardized index of liking (Cronbach's $a=0.92$ ), and the results by condition are depicted in Figure 2. The results replicate the effect found in Study 1: participants liked high question-askers $(M=6.02, S D=$ $0.74)$ more than low question-askers $(M=5.79, S D=0.97$; two-sample t-test: $t(336)=2.46, p=$ .014 ; Cohen's $d=0.27$ ). We also conducted a multiple regression to test for an interaction between experimental conditions. This analysis revealed that the effect of question-asking was no different between the two conditions (interaction term: $\beta=.108, S E=.190 ; t(334)=.57, p=$ .569), which implies that the effect of question-asking is robust to variations in question-asking from the person being asked.

Predicted liking. We tested whether participants anticipated the effects of questionasking, using the same standardized index of predicted liking as in Study 1 (Cronbach's $a=$ 0.92). Participants assigned to ask many questions did not think they would be liked any more $(M=5.16, S D=0.90)$ than participants assigned to ask few questions $(M=5.22, S D=1.00$; twosample t-test: $t(336)=0.54, p=.588)$. When the data from all conditions were pooled, there was also no correlation between question-asking and predicted liking $(r=-0.067, t(336)=1.23, p=$ 
0.221). These results provide further evidence that the positive effect of question-asking on liking is not anticipated by the askers.

Total words. For each participant, we calculated the total number of words written during the chat (using the R package "qdap"). We fit a hierarchical linear model, controlling for dyad, with total words as the dependent variable, and self and partner question asking as the independent variables. The model revealed a significant main effect of partner question asking. Participants whose partner was instructed to ask a high number of questions wrote more words ( $\beta$ $=31.07, S E=9.58, t(291.1)=3.24, p=.001)$ than did participants whose partner was instructed to ask a low number of questions. There was no significant main effect of one's own level of question-asking on total words written $(\beta=-12.54, S E=9.58, t(291.1)=1.31, p=.192)$.

Next, we tested whether the difference in total words mediated the relationship between partner question-asking and liking toward one's partner. We fit a linear mediation model bootstrapped over 5000 simulations, with liking as the dependent variable and partner condition as the independent variable (Imai, Keele, Tingley, \& Yamamoto, 2010). This model is shown in Figure 3, and shows a significant mediation of the treatment effect through word count $(\beta=.094$, $95 \% C I=[.033, .166], p=.002)$. After including total words in the model, the residual direct effect of condition $(\beta=.139,95 \% C I=[-.040, .320], p=.126)$ was not statistically significant.

\section{Discussion}

In Study 2, we found that question-asking increased liking in a 15-minute conversation between two people. People whose partner asked them a high number of questions liked their partner more than people whose partner asked them a low number of questions. One's own question-asking does not affect liking of one's partner. Furthermore, we found evidence for a mechanism underlying this effect: receiving many questions increased the number of words 
written by participants, which in turn increased liking for the high question asker. It seems being asked questions increased self-disclosure, which increased liking. These results suggest that people may like question-askers because they enjoy talking about themselves and their own perspectives.

Additionally, Study 2 shows that people did not anticipate the effect of question-asking on liking. This could be because they were too preoccupied with the spontaneous give-and-take of the conversation to explicitly consider how their question-asking behavior would affect the other person's perceptions of them. In Study 3, we test whether people anticipate this effect when they are more reflective - that is, when they are observing a conversation rather than participating in one.

\section{Study 3}

In Study 3, we test how third-party observers perceive question-asking in conversations. One possibility is that question-asking fosters positive inferences about the asker (e.g. that they are curious or empathic). If that is true, then the effect of question-asking should also be present in third-party observers. However, if question-asking increases liking during a conversation because it invites self-disclosure, then the effect should not hold in third-party observers, since they are not answering the questions themselves.

Another advantage of this design is that third-party observers are not focused on maintaining the dialogue and can take an outside view of the conversation, unlike the speakers themselves.

\section{Method}

Participants. We recruited 644 participants from Amazon's Mechanical Turk who participated in exchange for $\$ 0.50$. We included 612 participants (373 male, 239 female) in the 
analysis. We excluded 30 participants with duplicate IP addresses and two participants who reported that they could not read the chat conversation. Exclusion criteria were determined $a$ priori.

Design and procedure. Participants were randomly assigned to read the transcript of one of the 169 conversations from Study 2. Participants then reported their own liking of both conversation partners and their prediction of how much each person liked their partner, using the same sets of measures as in Study 2. These questions were grouped into two blocks - reported liking and predicted liking - and the order of these blocks was counterbalanced. Next, participants reported their estimates of how many questions each partner asked.

\section{Results}

Each of the 169 conversations was viewed by at least three different independent observers. We combined the observers' ratings exactly as in Study 2: that is, every observer's own liking and predicted liking for both people in the conversation were calculated at the individual level, as a standardized index across the set of four liking items.

In general, observers who rated the same conversations tended to agree with one another, with high intra-class correlations for reported liking $(\mathrm{ICC}=.810)$ and predicted liking by each partner toward the other partner (ICC=.876). To test the effect of question-asking on third-party ratings, the observer ratings were entered into a hierarchical linear model, with their rating as the dependent variable, and rater and dyad fixed effects included as control variables. This allowed us to make a precise estimate of how third-party perceptions were influenced by the questionasking instructions.

Third-party liking. Across the conversations, third-party observers reported a mean liking of $5.41(S D=1.03)$ toward each conversationalist. When each conversationalist's own 
condition was entered as a predictor in the hierarchical model, the results showed that people who were assigned to ask more questions were not liked any more than people who were assigned to ask fewer questions $(\beta=-0.043, S E=0.037, t(743.6)=1.18, p=0.240)$. This shows that question-asking did not induce liking from outside observers in the same way that it affected the other person in the conversation.

Interestingly, we did find that third-party observers preferred question answerers more. In our results, third-party observers liked people whose partner was instructed to ask many questions more than people whose partner was instructed to ask few questions $(\beta=0.075, S E=$ $0.037, t(745)=2.05, p=0.041)$. This suggests that question-answering, rather than questionasking, makes a conversationalist more appealing to third parties.

Third-party predicted liking. Across the conversations, third-party observers reported a mean predicted liking of $5.59(S D=0.95)$ by one partner for the other partner. When each conversationalist's own condition was entered as a predictor in the hierarchical model, the results showed that neither own question-asking $(\beta=0.009, S E=0.030, t(699)=0.29, p=0.773)$, nor partner question-asking $(\beta=-0.006, S E=0.029, t(699)=0.19, p=0.847)$ influenced predicted liking. These results show that outside observers also did not anticipate that being asked many questions would increase liking for one's partner.

\section{Discussion}

The primary goal of Study 3 was to investigate the mechanism of question-asking on liking. We found that for third-party observers, the effect of question-asking on liking of the question-asker disappears. These results provide further evidence that people like questionaskers because they enjoy self-disclosing. That is, people only like question-askers when the questions are directed toward them personally and they have the opportunity to answer. 
Furthermore, we find that the effect of question-asking reverses for a third-party observer. Third-party observers liked the person who received more questions compared to the person who received fewer questions. In other words, when you are participating in a conversation, you like the person who asks more questions. When you are observing a conversation, you like the person who answers more questions. One explanation is that because the recipients of a high number of questions responded with more words, third-party observers received more information about those participants and potentially found them to be more interesting.

A further goal of Study 3 was to examine lay predictions regarding the benefits of question-asking for individuals not immersed in conversation. Though we found in Study 2 that asking questions increases liking by question recipients for question askers, third-party observers failed to accurately predict the effect of question-asking on liking between the conversation partners.

\section{Study 4}

In Studies 1 and 2, we found that being asked questions increases self-disclosure and increases liking from the question answerer toward the question asker. However, third-party observers like conversationalists who answer more questions. In Study 4, we examine the effect of question-asking on a behavioral outcome, getting asked on a second date, in a real-world setting of speed-dating.

In this study, we use data from a previous investigation of speed-dating (Jurafsky, Ranganath, \& McFarland, 2009; Ranganath, Jurafsky, \& McFarland, 2009, 2013). Speed-dating is an ideal environment to test this effect because 1) speed daters are highly motivated to make a positive first impression on their conversational partners, and 2) each speed dater interacts with 
many other partners, which allows us to separate dyad-level effects from individual differences in question-asking.

\section{Method}

We examine data from a previously published investigation of speed-dating (Jurafsky et al., 2009; Ranganath et al., 2009, 2013). One hundred and ten men and women were gathered in three different sessions. Each dater went on 15-19 four-minute speed dates during a session. Every person wore a microphone to capture the dialogue during the dates. After each date, participants filled out a brief survey about their most recent partner, and indicated whether they would want a follow-up date. If both people in a pair wanted a second date, the experimenters provided them with one another's contact information (see Jurafsky et al. [2013] for full description of methods).

Our primary dependent variable was participants' willingness to go on a second date, recorded as a binary response (yes/no). Our primary independent variable was the number of questions each person asked on each date. As in previous studies, we measured question-asking by counting conversational turns that included a question mark.

\section{Results}

Our analyses focus on the 1,961 unique observations for which we had a complete postdate survey and a matching transcript. Across these observations, $46.8 \%$ of participants were willing to go on a second date with their partner, although there was also a large gender gap: men wanted second dates with $56.8 \%$ of their partners, but women only wanted second dates with $36.9 \%$ of their partners, on average.

Practically all of the dates were filled with active conversation, and questions were common. On an average date, each person asked 10.8 questions, which means that roughly $24 \%$ 
of their conversational turns included a question. Though these speed dates were shorter than the conversations in Studies 1 and 2, they produced a similar amount of dialogue, presumably because participants were interacting verbally face-to-face. Conversation length and question counts were correlated, as expected $(r=.304, t(1959)=14.1, p<.001)$, so we conducted our analyses using both the raw number of questions per date and the rate of questions as a fraction of the total number of conversational turns in the date. Question-asking was a relatively stable trait across individuals. That is, the best predictor of someone's question rate on any given speed date was their question rate on other dates $(r=.388, t(1959)=18.6, p<.001)$.

We compared the rate of question-asking to the second-date "success rate" to see whether asking questions had an impact on making a positive impression. The average question rate per person $(N=110)$ is plotted in Figure 4 against the adjusted measure of success rate: the percentage of second dates per date, accounting for partner-level fixed effects. The adjusted rate accounts for the fact that some speed daters are pickier than others; in particular, female partners are far pickier than male partners. In the plot, the trend is clear: people who ask more questions get more dates.

We used logistic regression to test the statistical significance of these effects (see Table 1). These models treat each yes/no second-date decision as an observation $(N=1961)$, and we report several models in order to conduct various robustness checks. There are two different dependent variables: total questions per date (in columns 1, 3, and 5), and questions per conversational turn (in columns 2, 4, and 6). We also report three levels of partner effects. There are baseline OLS regressions with no other predictors (columns 1 and 2). There are also multiple regressions, which control for gender as a covariate (columns 3 and 4). Finally, there are hierarchical regressions, which include partner fixed effects (columns 5 and 6). Our results show 
that the effect of question-asking on speed date success is positive and robust to model specification. While gender and question-asking each had a main effect on success rates, there was no interaction. That is, question-asking was an equally successful strategy for men and women.

\section{Discussion}

The results of Study 4 demonstrate a similar main effect as in Studies 1 and 2 in a realworld setting: speed dating. People who asked more questions were asked on more second dates, a straightforward indicator of interpersonal liking. The regression estimates imply that an average person in this sample who asks five more questions per date over an evening of 20 speed dates should expect to achieve "success" on one additional date. Despite the correlational nature of these data, we believe that they provide further evidence that question-asking can improve impression formation, even in high-stakes real-world settings.

\section{General Discussion}

Conversations are complex social interactions, fraught with decisions about what to say and how to behave. Although every adult has decades of experience conversing with others, our data suggest that people often fail to engage in behaviors that will help them make the most positive impression or learn the most from their conversation partners. While prior data demonstrate that people tend to talk about themselves (Dunbar et al, 1997; Marr \& Cable, 2014), we find instead that question-asking increases liking because it invites the partner to talk (H1). Our results suggest that individuals have an incorrect (or at least, an incomplete) lay theory about the role of questions in conversation.

Furthermore, we identify an important psychological mechanism driving this effect: Question-asking increases self-disclosure, which is intrinsically enjoyable. Question responders 
likely attribute this enjoyment to the question-asker, increasing liking. Using mediation analyses, we find that receiving a higher number of questions increases self-disclosure, measured by the total number of words spoken by the responder during the conversation. The total word count mediates the relationship between question-asking and liking of the question-asker (H3).

By asking third-party observers to rate conversations, we distinguish between whether people like the question asker because question-asking is inherently likable (for example by signaling interest, empathy, or superior social skills), or because question-asking invites the question responder to self-disclose. Increased liking for question-askers disappears when they are rated by third-party observers (H4). This finding supports the idea that people like questionaskers because they enjoy self-disclosing. In sum, these results provide converging evidence that people like question-askers because they enjoy talking about themselves.

In this research, we wondered if people fail to ask questions because they do not anticipate the benefits or because the enjoyment of talking about the self conflicts with the motivation to make a positive impression by asking questions. We find evidence that conversationalists do not anticipate the effect of question-asking on liking when participating in a conversation. Even when given the opportunity to observe and reflect on a conversation, people fail to accurately predict the effect of question-asking on liking between conversationalists. Thus, it seems that people are largely unaware that asking questions has social benefits (H2).

Lastly, we investigate conversations in the ecologically valid context of speed-dating, where people are motivated to make a good impression during a first encounter. Our behavioral measure of liking is the decision to interact with the person again in the future. We find that for both men and women, question-asking robustly predicts getting asked on a second date (H1). Furthermore, we find evidence that question-asking is a relatively stable trait across individuals. 
People seek out opportunities to disclose to other people, and question-asking is a desirable trait that people seek in their partners.

\section{Theoretical Implications}

Our work contributes to the understanding of how self-disclosure takes place within the context of conversations. In initial interactions, self-disclosure predicts the likelihood of future interaction (Berscheid \& Regan, 2005; Derlega, Winstead \& Greene, 2008) as well as the development of close relationships (Altman \& Taylor, 1973). Self-disclosure is important during brief conversations with strangers and acquaintances (Brewer \& Mittelman, 1980), satisfying the human need to connect with other people (Baumeister \& Leary, 1995). The process of interacting with another person affects outcomes such as attraction and intimacy in longer-term relationships (Davis \& Perkowitz, 1979; McAllister, 1980; Miller et al., 1983; Reis \& Shaver, 1988; Reis, Clark, \& Holmes, 2004). Although self-disclosure is an interpersonal process, most prior studies examine self-disclosure absent the context of a conversation. Our research expands our understanding by looking at dyads. We suggest a social model of self-disclosure between a question-asker and a discloser. Instead of studying self-disclosure as an isolated event, we investigate the decision to ask a question, which precedes the decision to self-disclose, putting self-disclosure into a dynamic context.

Although some of our experiments randomly manipulate the decision to ask questions in conversation, in the real world, this decision is not exogenous and may be influenced by many contextual or person-level factors. In our speed-dating study, we find evidence that questionasking is a relatively stable trait across individuals. This result is consistent with prior work showing that being an "opener" in conversation is a stable trait within individuals (Miller et al., 1983). Although context was controlled in our experiments, we also found evidence for one 
contextual factor: time. Specifically, in every one of our studies, people asked more questions early in their conversation, and the question rate drifted downward throughout (though the rate of speech remained constant). However, these are not the only drivers of question-asking, and more research is needed.

Although question-asking is a relatively stable trait across individuals, people can learn to ask more questions. In Studies 1-2, we manipulated question-asking, showing that it is remarkably easy to nudge people to ask more questions. This suggests that question-asking is a skill that may be learned. For example, if a person consistently receives positive feedback (such as liking from the other person, or more second dates) for asking more questions during a conversation, she could learn to associate question-asking with positive outcomes. A history of rewards associated with question-asking during social interactions could change her conversational behavior. Over time, given a choice to talk about oneself or ask more questions in a conversation, a person could tend to choose the latter.

Furthermore, our findings illuminate the psychology of the discloser in a conversation. Although people enjoy self-disclosing, they enjoy self-disclosing even more when another person invites the disclosure. Extant research shows that experimenter-induced self-disclosure increases liking for the other person in a dyadic interaction (Collins \& Miller, 1994; Jourard, 1959). Our research suggests that this effect also holds when that disclosure is (more naturally) solicited by the other person within a free-flowing conversation. Although people may always choose to talk about themselves spontaneously, they will do so more when they are invited by another person and will like this other person more as a result. Indeed, social closeness increases as people reciprocally answer questions that grow increasingly more intimate (Aron et al., 1997; 
Sedikides, Campbell, Reader, \& Elliot, 1999). Our results show that question-askers are better liked, even if those questions do not elicit intimate information.

Very little research has investigated the importance of another person inviting or listening to the self-disclosure. People place monetary value on self-disclosing and even more monetary value on self-disclosing to another person (Tamir \& Mitchell, 2012), and they prefer an invitation to self-disclose rather than volunteering (or imposing) self-disclosure. People want to be heard and validated by others (Davis \& Perkowitz, 1979; Laurenceau et al., 1998; Reis \& Patrick, 1996; Reis \& Shaver, 1988), exhibiting a basic desire to share information with others (Tamir, Zaki, \& Mitchell, 2015). The question-asker, by giving the opportunity to talk about oneself, serves a validating role as the recipient of one's thoughts. The question-asker becomes a valuable conversation partner-indeed, one whom people want to interact with in the futuredue to our intrinsic desire to communicate our thoughts, feelings, and beliefs to other human beings.

Finally, our work opens a new research topic on the psychology of conversation, a pervasive human experience. We contribute a new methodology for studying conversations using software (ChatPlat) that facilitates and captures the text of live conversations.

\section{Limitations and Future Directions}

In this work, we find evidence for self-disclosure as the mechanism for liking the question-asker, but there could be additional mechanisms. First, people could enjoy the experience of self-disclosing and think that the other person is genuinely interested. Questionaskers could be perceived as more curious about other people's lives. Future research could test these two factors and their potential interaction. People may especially enjoy disclosing to those who seem genuinely interested in hearing what they have to say. 
Second, it is important to disentangle two possible mechanisms for the effect of questionasking on liking: the question-asker's interest and the question-responder's self-disclosure. When the other person asks a question, you could perceive that person as highly interested in you as a person. At the same time, you could enjoy answering that person's question. One way to disentangle these effects is to design an experiment where the participant knows that the other person chose a random question or random statement as their turn in the conversation. In this way, it seems like the partner's chosen questions/statements aren't genuine. If the effect of question-asking on liking still holds for randomly-chosen questions, that would further support self-disclosure as the mechanism explaining the effect.

Third, if a conversational partner asks a question, the receiver may infer liking from the partner. Therefore, the receiver could like the question-asker back by reciprocity. The reciprocation of liking — that is, we like others who show liking for us - has been extensively demonstrated (Montoya \& Insko, 2008; Gouldner, 1960; Wilson \& Henzlik, 1986; Sprecher, 1998). Fourth, the question-receiver may infer from her own extensive self-disclosure that she likes the question-asker. That is, she could rationalize her self-disclosure by inferring liking for the other person. In general, there are many causal factors that could feed back on each other so that question-asking increases liking. These multiple possible mechanisms that merit further investigation.

The relationship between question-asking and interpersonal liking may be not be monotonic - it may be curvilinear. That is, it may be the case that one can ask too many questions, annoying the conversation partner while not revealing sufficient information about oneself. When one asks too many questions without reciprocating self-disclosure, liking may decrease. People do not want to talk about themselves indefinitely without reciprocity, since self- 
disclosure should induce the other person to self-disclose as well (Cozby, 1972; Dindia, 1988, 2002; Jourard, 1971; Sprecher et al., 2013). Indeed, prior research suggests that higher turntaking in reciprocal self-disclosure increases liking (Sprecher et al., 2013).

A person who asks too many questions would likely be contributing less to the content of the conversation. By not presenting enough challenge or novelty (e.g., Silva, 2008), the questionasker may be perceived as less interesting, defensive, or overly-private. In our data, third-party observers preferred question answerers, presumably because those seemed like more complete, interesting people. Therefore, there is likely an optimal balance between question-asking and question-answering. To test this idea, future work should test question-asking dynamics at the extremes. What happens when someone asks zero questions? What happens when someone asks fifty?

Our analyses demonstrate a clear effect of the quantity of questions asked irrespective of question type. But the types of question one asks are likely to matter. In the current research, participants were instructed to get to know one another and tended to ask questions to solicit autobiographical information, such as interests, hobbies, and background. Information-seeking questions differ based on the amount and type of information sought (Graesser, 1985; Miles, 2013; Schegloff, 2007). General-inquiry questions, compared to confirmatory questions (which request a yes-no response), allow the other person to provide longer responses and in a selfdirected manner (Heritage \& Robinson, 2006; Minson, Ruedy, \& Schweitzer, 2011). Future work could investigate whether general-inquiry questions, compared to confirmatory questions, more effectively increase liking.

Along these same lines, there are certainly some types of questions that would not engender liking. For example, rude questions could degrade the quality of a conversation. But 
rude statements can be equally jarring, so it is not clear whether this is a moderator of questionasking per se or a simple effect of semantic content (i.e., rude vs. polite). Similarly, one might expect self-focused questions (e.g., "Did you like my cooking?") to decrease liking by conveying insecurity or not encouraging honest self-disclosure from the question responder. We leave ideas about question type as a fruitful avenue for future research.

Although there are benefits of question-asking, our findings suggest that people fail to ask enough questions. Why might people forego asking questions in dyadic conversation? First, given that people tend to be egocentric, they may not think to ask questions of their conversation partners at all because they are too focused on their own thoughts, feelings, and beliefs (e.g., Gilovich et al., 2000). We find that people do not anticipate the effects of question-asking. Second, people may realize they can ask questions but have too little interest, care, or curiosity to hear the answers. They may lack social curiosity, defined as "interest in how other people behave, think, and feel” (Renner, 2006, p. 305).

Third, people may want to ask questions but perceive social costs to asking questions. For instance, asking for help feels awkward and embarrassing (Bohns \& Flynn, 2010; DePaulo \& Fisher, 1980). People fear appearing incompetent when asking others for advice (Brooks et al., 2015) and may hesitate to ask questions because they fear rejection from others (Downey \& Feldman, 1996). In the classroom, students could worry that question-asking shows ignorance (Graesser, McMahen, \& Johnson, 1994). Indeed, when placed in private tutoring settings compared to the public arena of the classroom, student question-asking increases to ten questions per hour (Graesser, Person, \& Huber, 1993). This could be evidence that question-asking increases when the risk of embarrassment, such as the number of people observing, decreases. Furthermore, people may worry about making a negative impression by asking the "wrong" 
questions - those that could be perceived as rude, inappropriate, or intrusive. In sum, people may underweight the benefits of question-asking, overweight the benefits, or both.

\section{Conclusions}

People spend most of their time during conversations talking about their own viewpoints and tend to self-promote when meeting people for the first time. In contrast, high questionaskers - those that probe for information from others - are better liked and tend to learn more accurate information about others. Although most people don't anticipate the effects of questionasking and do not ask enough questions, people would do well to learn that it doesn't hurt to ask. 


\section{References}

Altman, I., \& Taylor, D. A. (1973). Social penetration: The development of interpersonal relationships. Oxford, England: Holt, Rinehart \& Winston.

Archer, R. L. (1979). Role of personality and the social situation. In G. J. Chelune (Ed.), Selfdisclosure: Origins, patterns, and implications of openness in interpersonal relationships (pp. 28-58). San Francisco: Jossey-Bass.

Aron, A., Melinat, E., Aron, E. N., Vallone, R. D., \& Bator, R. J. (1997). The experimental generation of interpersonal closeness: A procedure and some preliminary findings. Personality and Social Psychology Bulletin, 23(4), 363-377.

Baumeister, R. F., \& Leary, M. R. (1995). The need to belong: Desire for interpersonal attachments as a fundamental human motivation. Psychological Bulletin, 117(3), 497-529.

Baumeister, R. F. (1982). A self-presentational view of social phenomena. Psychological Bulletin, 91(1), 3-26.

Berger, C. R., \& Calabrese, R. J. (1975). Some explorations in initial interaction and beyond: Toward a developmental theory of interpersonal communication. Human Communication Research, 1(2), 99-112.

Berman, J. Z., Levine, E. E., Barasch, A., \& Small, D. A. (2015). The braggart's dilemma: On the social rewards and penalties of advertising prosocial behavior. Journal of Marketing Research, 52(1), 90-104.

Berscheid, E., \& Regan, P. (2005). The psychology of interpersonal relationships. Upper Saddle River, NJ: Prentice Hall.

Bertakis, K. D., Roter, D., \& Putnam, S. M. (1991). The relationship of physician medical interview style to patient satisfaction. The Journal of Family Practice, 32(2), 175-181.

Bohns, V., \& Flynn, F. J. (2010). "Why didn't you just ask?" Underestimating the discomfort of help-seeking. Journal of Experimental Social Psychology, 46(2), 402-409.

Brewer, M. B., \& Mittelman, J. (1980). Effects of normative control of self-disclosure on reciprocity. Journal of Personality, 48(1), 89-102.

Brooks, A. W., Gino, F., \& Schweitzer, M. E. (2015). Smart people ask for (my) advice: Seeking advice boosts perceptions of competence. Management Science, 61(6), 1421-1435.

Brooks, A. W., \& Schweitzer, M. E. (2011). Can Nervous Nelly negotiate? How anxiety causes negotiators to make low first offers, exit early, and earn less profit. Organizational Behavior and Human Decision Processes, 115(1), 43-54.

Chafe, W. L. (1970). Meaning and the structure of language. Chicago, IL; University of Chicago Press. 
Chaikin, A. L., \& Derlega, V. J. (1974). Variables affecting the appropriateness of selfdisclosure. Journal of Consulting and Clinical Psychology, 42(4), 588-593.

Chen, F. S., Minson, J. A., \& Tormala, Z. L. (2010). Tell me more: The effects of expressed interest on receptiveness during dialog. Journal of Experimental Social Psychology, 46(5), 850853.

Clark, H. H., \& Schaefer, E. F. (1989). Contributing to discourse. Cognitive Science, 13(2), 259294.

Collins, N. L., \& Miller, L. C. (1994). Self-disclosure and liking: A meta-analytic review. Psychological Bulletin, 116(3), 457-475.

Cozby, P. C. (1973). Self-disclosure: A literature review. Psychological Bulletin, 79(2), 73-91.

Davis, D., \& Perkowitz, W. T. (1979). Consequences of responsiveness in dyadic interaction: Effects of probability of response and proportion of content-related responses on interpersonal attraction. Journal of Personality and Social Psychology, 37(4), 534-550.

Davis, M. H. (1983). Measuring individual differences in empathy: Evidence for a multidimensional approach. Journal of Personality and Social Psychology, 44(1), 113-126.

DePaulo, B., \& Fisher, J. (1980). The costs of asking for help. Basic and Applied Social Psychology, 1, 23-35.

Derlega, V. J., Winstead, B. A., \& Greene, K. (2008). Self-disclosure and starting a close relationship. In S. Sprecher, A. Wenzel, \& J. Harvey (Eds.), Handbook of relationship beginnings (pp. 153-174). New York: Psychology Press.

Dibble, J. L., Levine, T. R., \& Park, H. S. (2012). The unidimensional relationship closeness scale (URCS): Reliability and validity evidence for a new measure of relationship closeness. Psychological Assessment, 24(3), 565-572.

Dillon, J. T. (1982). The multidisciplinary study of questioning. Journal of Educational Psychology, 74(2), 147-161.

Dillon, J. T. (1988). Questioning and teaching: A manual of practice. New York: Teachers College Press.

Dindia, K. (1988). A comparison of several statistical tests of reciprocity of self-disclosure. Communication Research, 15, 726-752.

Dindia, K. (2002). Self-disclosure research: Knowledge through meta-analyses. In M. Allen, R. W. Preiss, B. M. Gagle, \& N. Burrell (Eds.), Interpersonal communication: Advances through meta-analyses (pp. 169-186). Mahwah, NJ: Erlbaum.

Downey, G., \& Feldman, S. I. (1996). Implications of rejection sensitivity for intimate relationships. Journal of Personality and Social Psychology, 70(6), 1327-1343. 
Dunbar, R. I., Marriott, A., \& Duncan, N. D. (1997). Human conversational behavior. Human Nature, 8(3), 231-246.

Epley, N., \& Waytz, A. (2010). Mind perception. In Fiske, S. T., Gilbert, D. T., \& Lindzey, G. (Eds.), Handbook of social psychology (5 ${ }^{\text {th }}$ ed.) (pp. 498-541). New York: John Wiley \& Sons, Inc.

Frattaroli, J. (2006). Experimental disclosure and its moderators: A meta-analysis. Psychological Bulletin, 132(6), 823-865.

Gilovich, T., Medvec, V. H., \& Savitsky, K. (2000). The spotlight effect in social judgment: An egocentric bias in estimates of the salience of one's own actions and appearance. Journal of Personality and Social Psychology, 78(2), 211-222.

Godfrey, D. K., Jones, E. E., \& Lord, C. G. (1986). Self-promotion is not ingratiating. Journal of Personality and Social Psychology, 50(1), 106-115.

Gouldner, A. W. (1960). The norm of reciprocity: A preliminary statement. American Sociological Review, 25, 161-178.

Graesser, A. C. (1985). An introduction to the study of questioning. The psychology of questions, $1-14$.

Graesser, A. C., \& Clark, L. C. (1985). Structures and procedures of implicit knowledge. Norwood, NJ: Ablex.

Graesser, A. C., McMahen, C. L., \& Johnson, B. (1994). Question asking and answering. In M. A. Gernsbacher (Ed.), Handbook of psycholinguistics. San Diego, CA: Academic Press.

Graesser, A. C., Person, N. K., \& Huber, J. (1993). Question asking during tutoring and the design of educational software. In M. Rabinowitz, Cognitive science foundations for instruction (pp. 149-172). Hillsdale, NJ: Lawrence Erlbaum.

Grice, H. P. (1975). Logic and conversation. In P. Cole \& J. L. Morgan (Eds.), Syntax and semantics (Vol. 3, pp. 41-58). New York: Academic Press.

Heritage, J., \& Robinson, J. D. (2006). The structure of patients' presenting concerns: Physicians' opening questions. Health Communication, 19(2), 89-102.

Hilton, D. J. (1990). Conversational processes and causal explanation. Psychological Bulletin, 107(1), 65-81.

Imai, K., Keele, L., Tingley, D., \& Yamamoto, T. (2010). Causal mediation analysis using R. In Advances in social science research using $R$, 129-154. Springer New York.

Ireland, M. E., \& Pennebaker, J. W. (2010). Language style matching in writing: Synchrony in essays, correspondence, and poetry. Journal of Personality and Social Psychology, 99(3), 549571. 
Jones, E. E., \& Pittman, T. S. (1982). Toward a general theory of strategic self-presentation. In J. Suls (Ed.), Psychological perspectives on the self(Vol. 1, pp. 231-262). Hillsdale, NJ: Erlbaum.

Jourard, S. M. (1959). Self-disclosure and other-cathexis. The Journal of Abnormal and Social Psychology, 59(3), 428-431.

Jourard, S. M. (1971). The transparent self(rev. ed.). New York, NY: Van Nostrand Reinhold.

Jourard, S. M., \& Landsman, M. J. (1960). Cognition, cathexis, and the "dyadic effect" in men's self-disclosing behavior. Merrill-Palmer Quarterly of Behavior and Development, 6, 178-186.

Jourard, S. M., \& Lasakow, P. (1958). Some factors in self-disclosure. The Journal of Abnormal and Social Psychology, 56(1), 91-98.

Jourard, S. M. (1958). A study of self-disclosure. Scientific American, 198, 77-82.

Jurafsky, D., Ranganath, R., \& McFarland, D. (2009, May). Extracting social meaning: Identifying interactional style in spoken conversation. In Proceedings of Human Language Technologies: The 2009 Annual Conference of the North American Chapter of the Association for Computational Linguistics (pp. 638-646). Association for Computational Linguistics.

Kearsley, G. P. (1976). Questions and question asking in verbal discourse: A cross-disciplinary review. Journal of Psycholinguistic Research, 5(4), 355-375.

Landis, M. H., \& Burtt, H. E. (1924). A Study of Conversations. Journal of Comparative Psychology, 4(1), 81-89.

Laurenceau, J. P., Barrett, L. F., \& Pietromonaco, P. R. (1998). Intimacy as an interpersonal process: The importance of self-disclosure, partner disclosure, and perceived partner responsiveness in interpersonal exchanges. Journal of Personality and Social Psychology, 74(5), 1238-1251.

Leary, M. R., \& Kowalski, R. M. (1990). Impression management: A literature review and twocomponent model. Psychological Bulletin, 107(1), 34-47.

Lyubomirsky, S., Sousa, L., \& Dickerhoof, R. (2006). The costs and benefits of writing, talking, and thinking about life's triumphs and defeats. Journal of Personality and Social Psychology, 90(4), 692-708.

Marr, J. C., \& Cable, D. M. (2014). Do interviewers sell themselves short? The effects of selling orientation on interviewers' judgments. Academy of Management Journal, 57(3), 624-651.

McAllister, H. A. (1980). Self-disclosure and liking: Effects for senders and receivers. Journal of Personality, 48(4), 409-418.

Miles, E. W. (2013). Developing strategies for asking questions in negotiation. Negotiation Journal, 29(4), 383-412.

Miller, L. C., Berg, J. H., \& Archer, R. L. (1983). Openers: Individuals who elicit intimate selfdisclosure. Journal of Personality and Social Psychology, 44(6), 1234-1244. 
Minson, J. A., Ruedy, N. E., \& Schweitzer, M. E. (2011, August). Ask (the right way) and you shall receive: The effect of question type on information disclosure and deception. Unpublished paper presented at the Academy of Management meeting, San Antonio, TX.

Montoya, R. M., \& Insko, C. A. (2008). Toward a more complete understanding of the reciprocity of liking effect. European Journal of Social Psychology, 38(3), 477-498.

Omarzu, J. (2000). A disclosure decision model: Determining how and when individuals will self-disclose. Personality and Social Psychology Review, 4(2), 174-185.

Pennebaker, J. W. (1985). Traumatic experience and psychosomatic disease: Exploring the roles of behavioural inhibition, obsession, and confiding. Canadian Psychology/Psychologie Canadienne, 26(2), 82-95.

Pennebaker, J. W . (1989). Stream of consciousness and stress: Levels of thinking. In J. S. Uleman \& J. A. Bargh (Eds.), The direction of thought: Limits of awareness, intention, and control (pp. 327-350). New York: Guilford Press.

Pennebaker, J. W. (1997). Writing about emotional experiences as a therapeutic process. Psychological Science, 8(3), 162-166.

Pryor, J. B., \& Kriss, M. (1977). The cognitive dynamics of salience in the attribution process. Journal of Personality and Social Psychology, 35(1), 49-55.

Ranganath, R., Jurafsky, D., \& McFarland, D. (2009). It's not you, it's me: Detecting flirting and its misperception in speed-dates. In Proceedings of the 2009 Conference on Empirical Methods in Natural Language Processing: Volume 1-Volume 1 (pp. 334-342). Association for Computational Linguistics.

Ranganath, R., Jurafsky, D., \& McFarland, D. A. (2013). Detecting friendly, flirtatious, awkward, and assertive speech in speed-dates. Computer Speech \& Language, 27(1), 89-115.

Reis, H. T., \& Patrick, B. C. (1996). Attachment and intimacy: Component processes. In E. T. Higgins \& A. W. Kruglanski (Eds.), Social psychology: Handbook of basic principles (pp. 523563). New York: Guilford Press.

Reis, H. T., \& Shaver, P. (1988). Intimacy as an interpersonal process. In S. Duck \& D. F. Hay (Eds.), Handbook of personal relationships: Theory, research, and interventions (pp. 367-389). Chichester, England: Wiley.

Reis, H. T., Clark, M. S., \& Holmes, J. G. (2004). Perceived partner responsiveness as an organizing construct in the study of intimacy and closeness. In D. Mashek \& A. P. Aron (Eds.), Handbook of closeness and intimacy (pp. 201-225). Mahwah, NJ: Erlbaum.

Renner, B. (2006). Curiosity about people: The development of a social curiosity measure in adults. Journal of Personality Assessment, 87(3), 305-316.

Robinson, J. D., \& Heritage, J. (2006). Physicians' opening questions and patients' satisfaction. Patient Education and Counseling, 60(3), 279-285. 
Rogers, T. \& Norton, M.I. (2011). The artful dodger: Answering the wrong question the right way. Journal of Experimental Psychology: Applied, 17(2), 139-147.

Rogers, T \& Norton, M.I. (2016). Artful paltering: The risks and rewards of using truthful statements to mislead others. Working Paper.

Rosenfeld, H. M. (1966). Approval-seeking and approval-inducing functions of verbal and nonverbal responses in the dyad. Journal of Personality and Social Psychology, 4(6), 597-605.

Roter, D. L., \& Hall, J. A. (1987). Physicians' interviewing styles and medical information obtained from patients. Journal of General Internal Medicine, 2(5), 325-329.

Schachter, S., \& Singer, J. (1962). Cognitive, social, and physiological determinants of emotional state. Psychological Review, 69(5), 379-399.

Schegloff, E. A. (2007). Sequence organization in interaction: Volume 1: A primer in conversation analysis (Vol. 1). Cambridge University Press.

Shrout, P. E., \& Fleiss, J. L. (1979). Intraclass correlations: Uses in assessing rater reliability. Psychological Bulletin, 86(2), 420-428.

Sedikides, C., Campbell, W. K., Reader, G. D., \& Elliot, A. J. (1999). The relationship closeness induction task. Representative Research in Social Psychology, 23, 1-4.

Sezer, O., Gino, F., \& Norton, M.I. (2015). Humblebragging: A distinct - and ineffective - selfpresentation strategy. Harvard Business School Working Paper No. 15-080.

Silvia, P. J. (2008). Interest-The curious emotion. Current Directions in Psychological Science, 17(1), 57-60.

Smith, E. R., \& Miller, F. D. (1979). Salience and the cognitive mediation of attribution. Journal of Personality and Social Psychology, 37(12), 2240-2252.

Sprecher, S. (1998). Insiders' perspectives on reasons for attraction to a close other. Social Psychology Quarterly, 61, 287-300.

Sprecher, S., Treger, S., Wondra, J. D., Hilaire, N., \& Wallpe, K. (2013). Taking turns: Reciprocal self-disclosure promotes liking in initial interactions. Journal of Experimental Social Psychology, 49(5), 860-866.

Stiles, W. B., Putnam, S. M., Wolf, M. H., \& James, S. A. (1979). Interaction exchange structure and patient satisfaction with medical interviews. Medical Care, 17(6), 667-681.

Surra, C. A., \& Longstreth, M. (1990). Similarity of outcomes, interdependence, and conflict in dating relationships. Journal of Personality and Social Psychology, 59(3), 501-516.

Swann Jr., W. B., \& Gill, M. J. (1997). Confidence and accuracy in person perception: Do we know what we think we know about our relationship partners? Journal of Personality and Social Psychology, 73(4), 747-757. 
Swann Jr., W. B., Stephenson, B., \& Pittman, T. S. (1981). Curiosity and control: On the determinants of the search for social knowledge. Journal of Personality and Social Psychology, 40(4), 635-642.

Tamir, D. I., \& Mitchell, J. P. (2012). Disclosing information about the self is intrinsically rewarding. Proceedings of the National Academy of Sciences, 109(21), 8038-8043.

Tamir, D. I., Zaki, J., \& Mitchell, J. P. (2015). Informing others is associated with behavioral and neural signatures of value. Journal of Experimental Psychology: General, 144(6), 1114-1123.

Van der Meij, H. (1987). Assumptions of information-seeking questions. Questioning Exchange, $1(2), 111-117$.

Vangelisti, A. L., Knapp, M. L., \& Daly, J. A. (1990). Conversational narcissism. Communications Monographs, 57(4), 251-274.

White, G. L., Fishbein, S., \& Rutsein, J. (1981). Passionate love and the misattribution of arousal. Journal of Personality and Social Psychology, 41(1), 56-62.

Wilson, W., \& Henzlik, W. (1986). Reciprocity of liking following face-to-face encounters with attractive and unattractive others. Psychological Reports, 59, 599-609. 


\section{Table 1}

Standardized logistic regression models predicting willingness to go on a date in Study 4.

\begin{tabular}{|c|c|c|c|c|c|c|}
\hline Predictors & $\underline{1}$ & $\underline{\mathbf{2}}$ & $\underline{\mathbf{3}}$ & $\underline{4}$ & $\underline{5}$ & $\underline{6}$ \\
\hline \multirow{2}{*}{$\begin{array}{l}\text { Total Number of } \\
\text { Questions }\end{array}$} & $.092 *$ & & $.159 * *$ & & $.252 * * *$ & \\
\hline & $(.045)$ & & $(.048)$ & & $(.060)$ & \\
\hline \multirow{2}{*}{ Question Rate } & & $.077^{\wedge}$ & & $.130 * *$ & & $.150^{*}$ \\
\hline & & $(.045)$ & & $(.047)$ & & $(.061)$ \\
\hline \multirow{2}{*}{$\begin{array}{l}\text { Partner Gender } \\
(1=\text { male })\end{array}$} & & & $.854 * * *$ & $.846 * * *$ & & \\
\hline & & & $(.094)$ & $(.094)$ & & \\
\hline \multirow{2}{*}{ Gender*Question } & & & .143 & -.049 & & \\
\hline & & & (.096) & (.094) & & \\
\hline Rater Fixed Effects & $\mathrm{NO}$ & $\mathrm{NO}$ & NO & NO & YES & YES \\
\hline $\begin{array}{l}\text { Dependent } \\
\text { Variable }\end{array}$ & $\begin{array}{l}\text { willing to } \\
\text { date again }\end{array}$ & $\begin{array}{l}\text { willing to } \\
\text { date again }\end{array}$ & $\begin{array}{l}\text { willing to } \\
\text { date again }\end{array}$ & $\begin{array}{l}\text { willing to } \\
\text { date again }\end{array}$ & $\begin{array}{l}\text { willing to } \\
\text { date again }\end{array}$ & $\begin{array}{l}\text { willing to } \\
\text { date again }\end{array}$ \\
\hline Observations & 1961 & 1961 & 1961 & 1961 & 1961 & 1961 \\
\hline pseudo- $\mathrm{R}^{2}$ & .002 & .001 & .034 & .032 & .139 & .135 \\
\hline
\end{tabular}

Legend (two-tailed): ${ }^{\wedge}=p<0.10 ; *=p<0.05 ; * *=p<0.01 ; * * *=p<0.005$ 


\section{Figure 1}

The effect of question-asking on liking in Study 1. In each pair, one person was randomly assigned to receive either few or many questions from the question-asker. Error bars represent $95 \%$ CI for the group means.

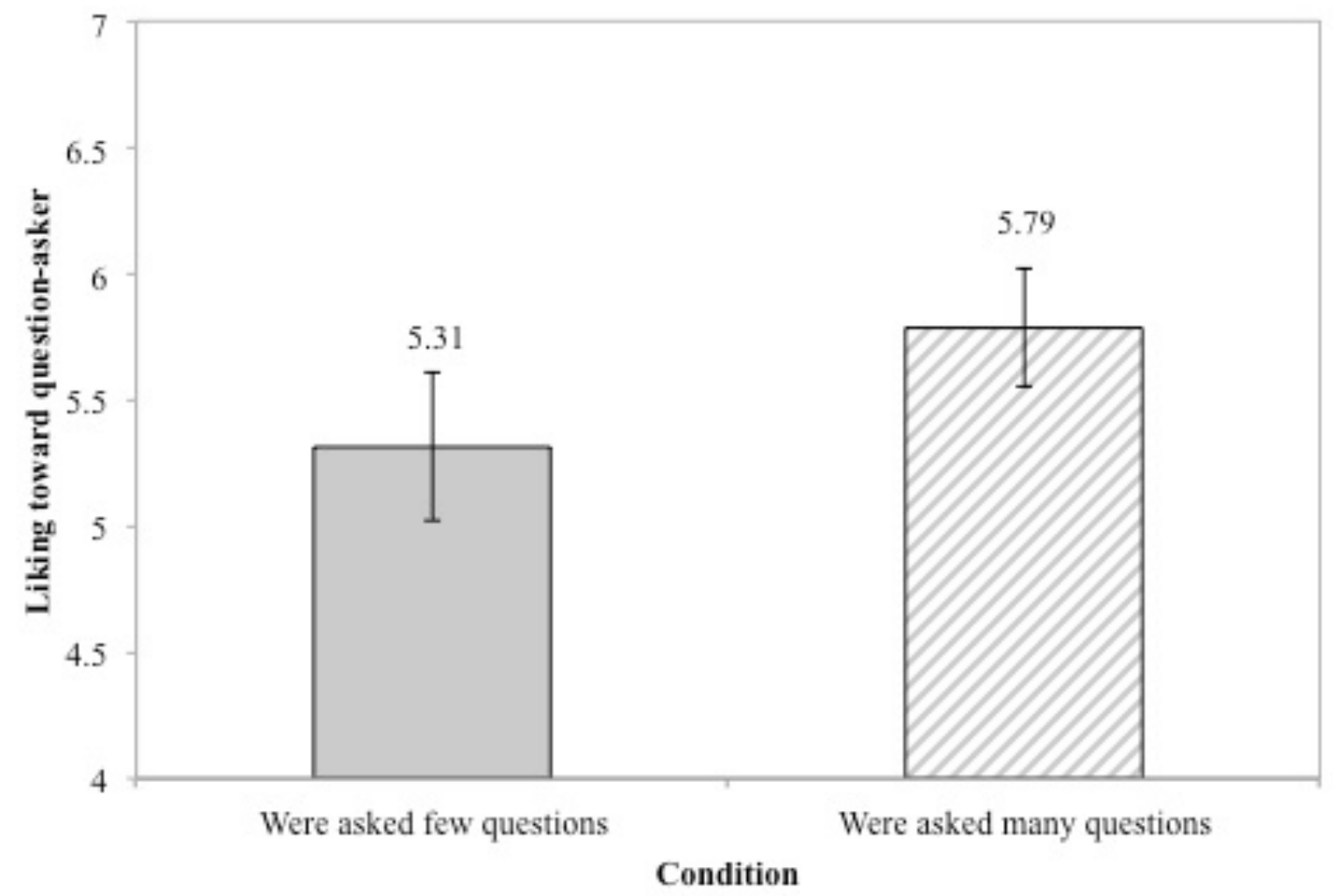




\section{Figure 2}

The effect of question-asking on liking in Study 2. Each participant was given questionasking instructions, such that each person's own instructions and partner's instructions were independently manipulated in a 2x2 design. Error bars represent 95\% CI for the group means.

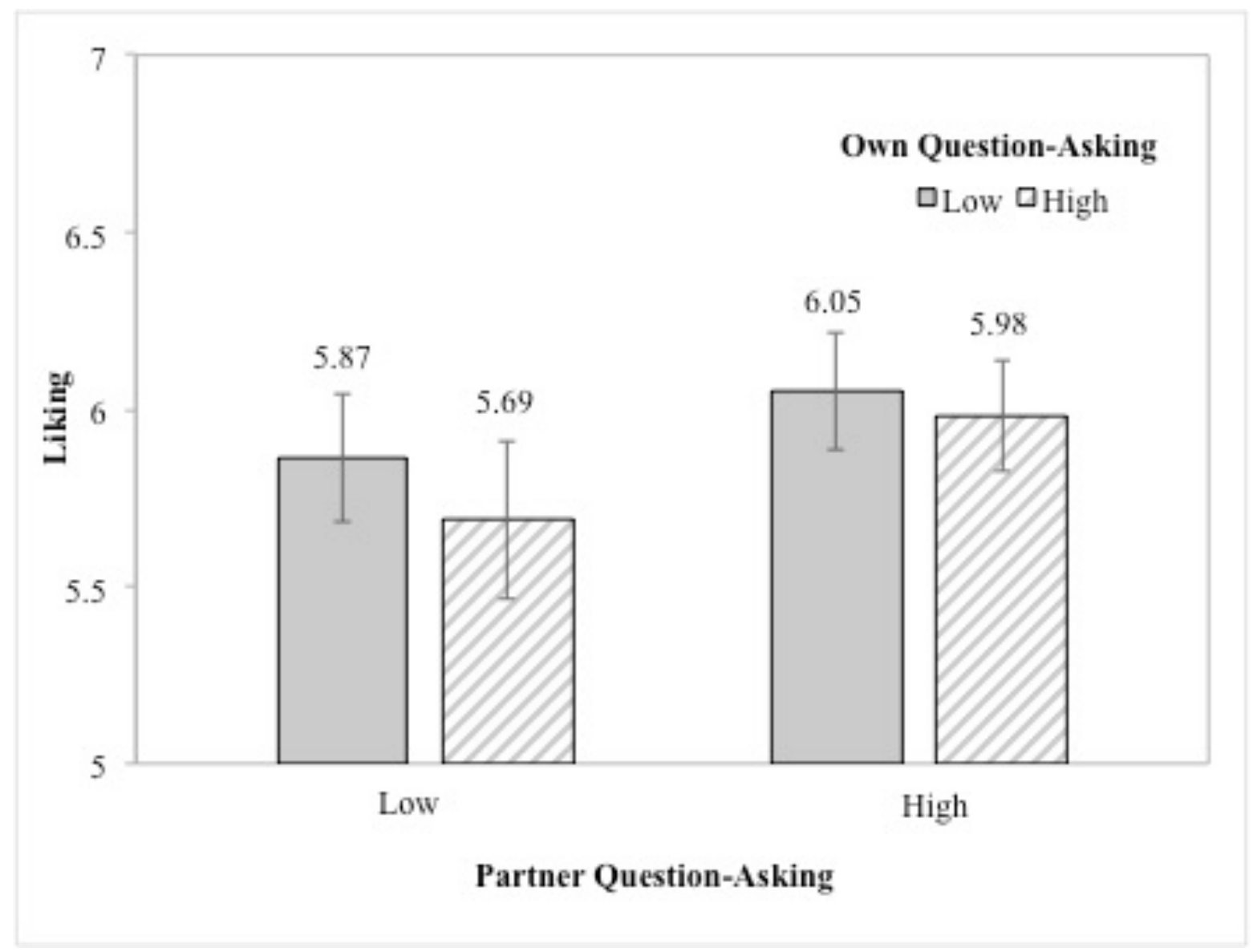




\section{Figure 3}

Mediation results from Study 2. Partner question-asking increases the total number of works spoken by oneself, as a measure of self-disclosure, which mediates the effect of partner question-asking on liking toward one's partner.

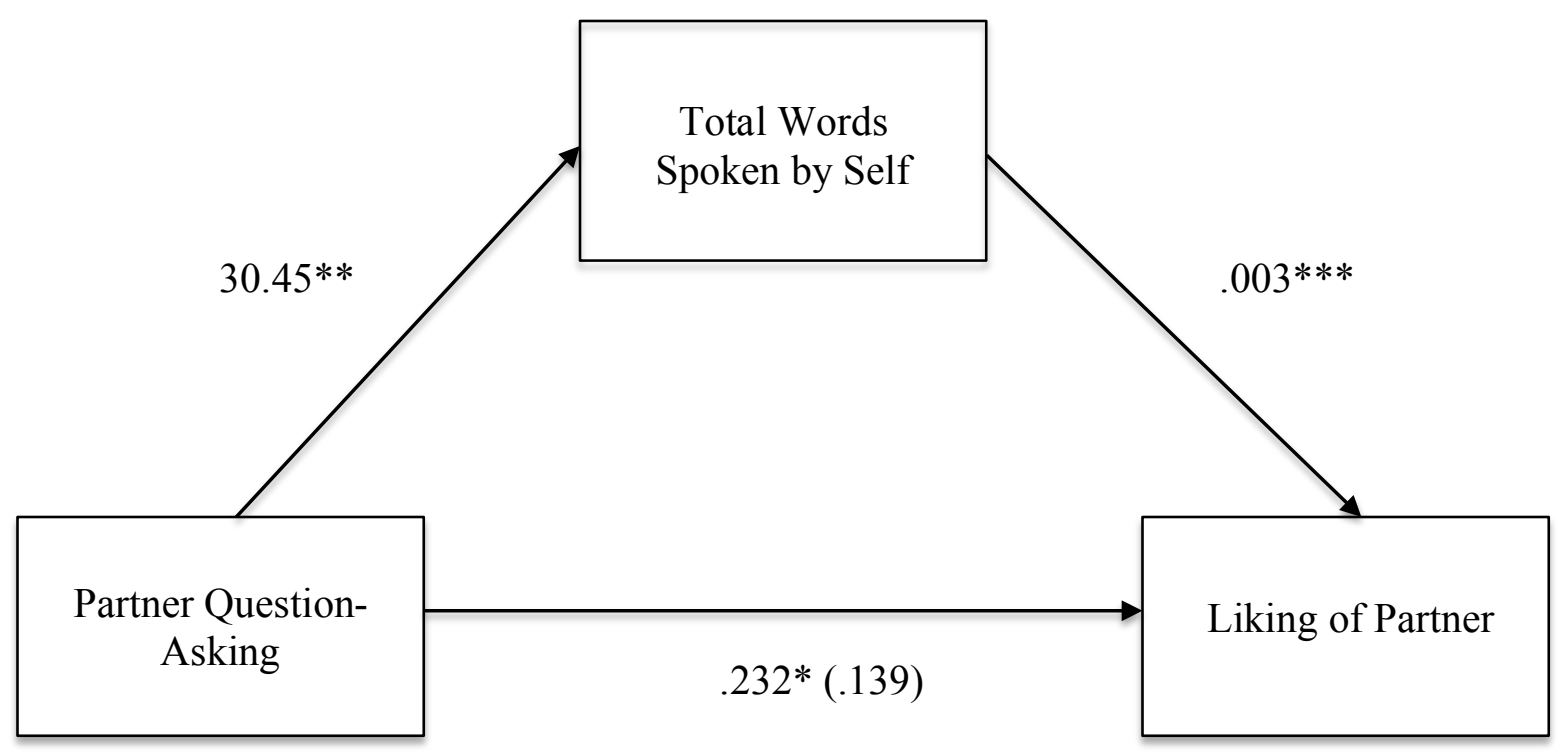

Legend: $* \mathrm{p}<.05 ; * * \mathrm{p}<.01 ; * * * \mathrm{p}<.001$ 


\section{Figure 4}

The effect of question-asking on dating outcomes in Study 4. Each point is one speed dater, and the $\mathrm{X}$ axis represents the average number of questions they asked per date (as a percentage of conversational turns) while the Y axis shows each person's speed dating success rate (i.e. getting second-date requests from their partners). The success rate is adjusted for partner fixed effects, which accounts for the wide gender disparity in the raw success rates (among other partner-level variables). The regression line represents the HLM fit on the adjusted data (error bands indicate $95 \% \mathrm{CI}$ of regression slope).

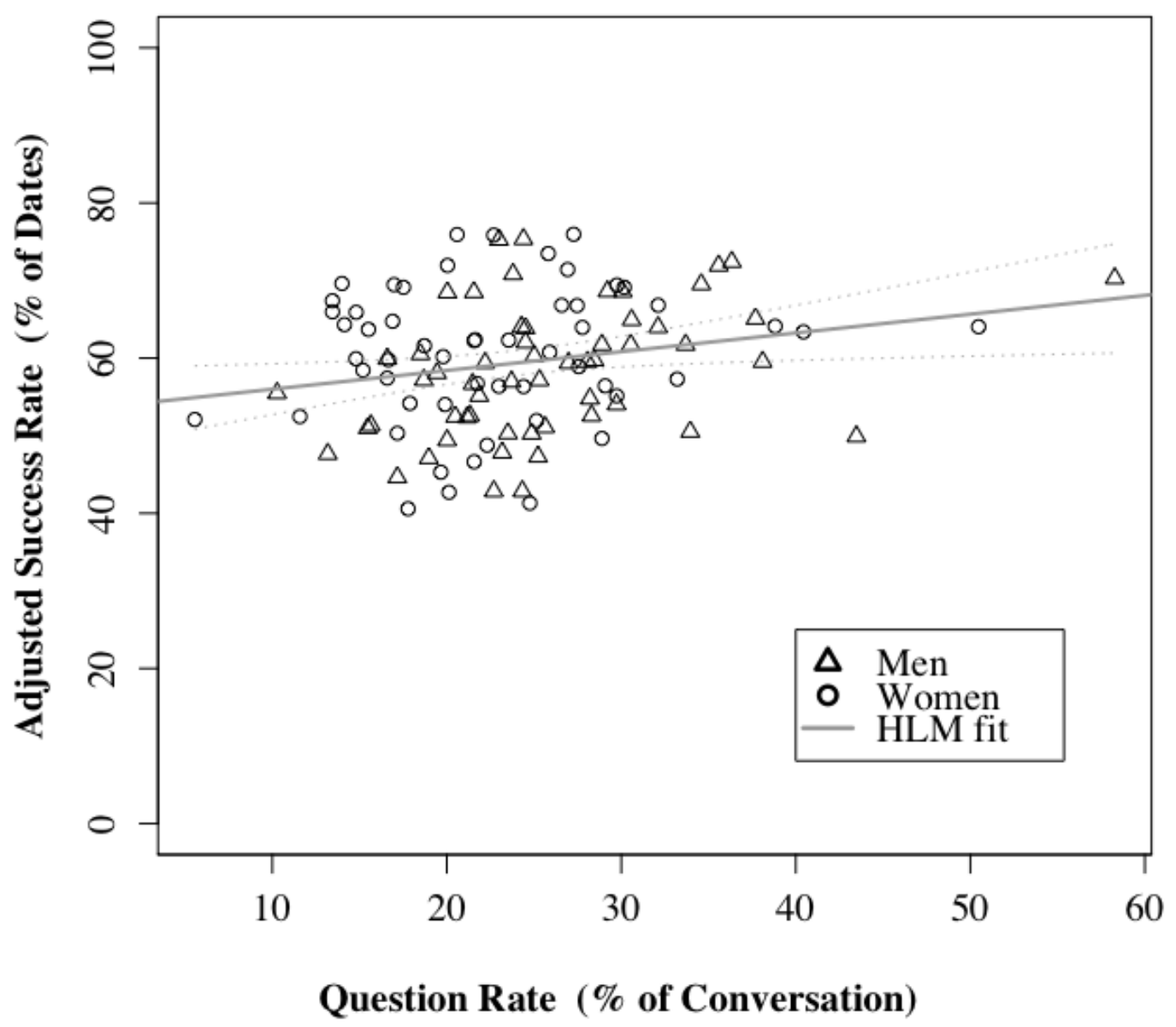


Authors' note: We report all measures that were collected during the studies. We discuss the findings from our main measures in the manuscript. Other measures reported below were nonsignificant, but we report them here for methodological transparency.

\section{Appendix A: Measures from Pilot Study}

\section{Paired}

Were you paired with another participant? Note: If there were technical issues with the chat, it will not affect your payment.

- Yes, I was joined in the chat with another participant.

- No, no one ever joined me in the chat.

\section{Learning}

What information did you learn about your partner during the conversation? Try to be as detailed as possible.

All the following measures are on the scale 1 (strongly disagree) to 7 (strongly agree) unless noted otherwise.

\section{Liking}

I liked my partner.

My partner is likeable.

I would enjoy spending time with my partner.

I dislike my partner. (reverse-scored)

\section{Enjoyment}

I enjoyed this conversation.

I thought this conversation was engaging.

I had an interesting conversation with this person.

Interest

This person is interesting.

I find it fascinating to get to know this person.

This person is not boring.

This person is engaging.

\section{Perceived Social Closeness}

Adapted from Unidimensional Relationship Closeness Scale (Dibble, Levine, \& Park, 2012) 
I feel close to this person

I would want to spend time with this person

I would connect well with this person

Perceived Curiosity

Adapted from Social Curiosity Scale (Renner, 2006)

This person is interested in learning more about me.

This person finds it fascinating to get to know new people.

This person likes finding out how people "work."

This person is interested in my thoughts and feelings.

My life stories interest this person.

This person is curious about me.

Empathy

Adapted from Davis, 1983

Perspective-taking

I understand this person's situation

I can imagine being in this person's place

I can easily imagine how things look from this person's perspective

Empathic concern

I feel warm toward this person

I feel compassion for this person

I feel sympathetic toward this person

I empathize with this person

Perceived Empathy

This person understands my situation.

This person can imagine being in my place.

This person can easily imagine how things look from my perspective.

This person feels warm toward me.

This person feels compassion for me.

This person feels sympathetic toward me.

This person empathizes with me.

\section{Listening}

I was a good listener during our conversation.

My partner was a good listener during our conversation. 


\section{Decision to Chat Again}

Would you like to have a conversation with this person again in the future? (Yes/No)

\section{Self vs. Other Focus}

During the conversation with your partner...

$(1=$ not at all, $4=$ some of the time $=7$ all of the time $)$

How much were you thinking about yourself?

How much were you thinking about the other person?

\section{Estimated Questions}

During the conversation with your partner, approximately how many questions did you ask? During the conversation with your partner, approximately how many questions did your partner ask?

Demographics

What is your gender? (Male/Female)

What is your age (in years)? 


\section{Appendix B: Measures from Study 1-3}

\section{Paired (Studies 1,2)}

Were you paired with another participant? Note: If there were technical issues with the chat, it will not affect your payment.

- Yes, I was joined in the chat with another participant.

- No, no one ever joined me in the chat.

\section{Chat Type (Studies 1,2)}

If you were paired with a participant, how would you best describe your interaction with the other participant? Note: Your responses will not affect your payment.

- The other participant and I had a full conversation.

- The other participant only said a few lines, then didn't respond.

- I only said a few lines, then didn't respond.

- The other participant only said a few lines, then left the chat.

- The other participant never responded.

- I never responded to the other participant.

Check (Study 3)

Were you able to read the conversation between User 1 and User 2? (Note: If you were not able to read the conversation, you will still be paid for participating in the study.) (Yes/No)

The following interpersonal perception measures are on 1-7 scales unless noted otherwise.

\section{APQ Self (Study 1)}

Please, tell us how much you enjoy doing each of the following activities. That is, give us your own, personal opinion for each question.

1 (Dislike Extremely) - 9 (Like Extremely)

Reading

Watching TV

Partying

Seeing live music

Watching sports

Playing board games

Cooking

Working out

Cleaning 


\section{APQ Partner (Study 1)}

We asked your partner to tell us how much they "enjoy doing each of the following activities." Now we'd like you to guess how your partner responded. That is, what answer did they just give to these exact questions?

(Same items as APQ Self)

Liking (Studies 1, 2)

My partner is likeable.

I liked my partner.

I would enjoy spending time with my partner.

I dislike my partner. (reverse-scored)

Predicted Liking (Studies 1,2)

My partner thinks I'm likeable.

My partner liked me.

My partner would enjoy spending time with me.

My partner dislikes me. (reverse-scored)

Ratings of Liking (Study 3)

Liking of User 1

User 1 is likeable.

I like User 1.

I would enjoy spending time with User 1.

I dislike User 1.

Liking of User 2

User 2 is likeable

I like User 2

I would enjoy spending time with User 2.

I dislike User 2.

Ratings of Predicted Liking (Study 3)

Prediction of User 1 's response

User 1 thinks User 2 is likeable. 
User 1 liked User 2.

User 1 would enjoy spending time with User 2.

User 1 dislikes User 2.

Prediction of User 2's response

User 2 thinks User 1 is likeable.

User 2 liked User 1.

User 2 would enjoy spending time with User 1.

User 2 dislikes User 1.

Enjoyment (Study 1)

I enjoyed this conversation.

I thought this conversation was engaging.

I had an interesting conversation with this person.

Predicted Enjoyment (Study 1)

My partner enjoyed this conversation.

My partner thought this conversation was engaging.

My partner had an interesting conversation with me.

Perspective-Taking (Study 2)

I understand this person's situation

I can imagine being in this person's place

I can easily imagine how things look from this person's perspective

Perceived Perspective-Taking (Study 2)

This person understands my situation.

This person can imagine being in my place.

This person can easily imagine how things look from my perspective.

Empathic Concern (Study 2)

I feel warm toward this person

I feel compassion for this person

I feel sympathetic toward this person

Perceived Empathic Concern (Study 2)

This person feels warm toward me.

This person feels compassion for me. 
This person feels sympathetic toward me.

Confidence (Study 1)

How well do you think you know what activities your partner would enjoy?

How well do you think your partner knows what activities you would enjoy?

Self-Other Similarity (Study 1)

How much do you think you have in common with your partner?

How similar do you think you and your partner are likely to be?

\section{Estimated Questions (Studies 1,2)}

During the conversation with your partner, how many questions did you ask? Please give your best estimate in the box below:

During the conversation with your partner, how many questions did your partner ask? Please give your best estimate in the box below:

Estimated Questions (Study 3)

In the conversation you just read, how many questions did User 1 ask? Please give your best estimate in the box below:

In the conversation you just read, how many questions did User 2 ask? Please give your best estimate in the box below:

Manipulation Check (Studies 1,2)

Were you given instructions to ask questions? (Yes/No)

How many questions were you instructed to ask?

Questions Wanted To Ask (Studies 1,2)

Did you want to ask more questions or fewer questions than you were instructed to ask?

(More/Fewer/About the same)

During the conversation with your partner, how many questions did you actually want to ask? Please enter a number in the box below:

\section{Demographics (Studies 1, 2, 3)}

What is your gender? (Male/Female)

What is your age (in years)? 


\section{Dictator Game (Study 2)}

You have been granted a $\$ 1.00$ bonus (in addition to your $\$ 2.00$ base pay for participating in this study).

You must now decide how much of the $\$ 1.00$ to give to your partner, and how much to keep for yourself. You get to keep the amount that you do not give to your partner.

You can give some, all, or none of the $\$ 1.00$ to your partner. Your partner will then keep the amount you give to them. (The payments are given after the survey is finished.)

Your partner will NOT know the amount of money you give until after the survey is finished. You will never see, meet, or interact with your partner in the future.

How much do you decide to give to your partner? Enter a number between $\$ 0.00$ and $\$ 1.00$ in the box below: 